E N S A I O B I B L I O G R Á F I C O

\title{
SOBRE A HISTÓRIA CONSTITUCIONAL
}

\author{
On Constitutional History
}

ANDREI KOERNER

http://dx.doi.org/10.1590/S2178-14942016000200011

Andrei Koerner é pofessor de Ciência Política na Unicamp, coordenador do GPD/Ceipoc e pesquisador do Cedec e do INCT/ Ineu. No ano acadêmico de 2015-16 é pesquisador convidado junto ao Institut des Hautes Etudes de l'Amerique Latine (IHEAL), da Université Sorbonne-Nouvelle, Paris III, com bolsa da Capes (andreik@uol.com.br).

Artigo recebido em 18 de maio e aprovado para publicação em 19 de maio de 2016. 


\section{RESUMO}

0 ensaio discute a produção bibliográfica europeia recente sobre a história constitucional. A partir da exploração de diversos sentidos da expressão, analisa três perspectivas: a jurídica, a positiva e a crítica, e discute sua abordagem, seus conceitos e métodos. Na conclusão, faz um balanço crítico das perspectivas e esboça 0 conceito de ordem constitucional para articular uma reflexão crítica sobre o direito e as técnicas de governo na atualidade.

PalaVras-ChaVe: história constitucional; direito e política; constituição; constitucionalismo.

\section{AbSTRACT}

The essay discusses the recent European bibliographic production concerning constitutional history. From the exploration of different meanings of the expression, it analyzes three perspectives: juridical, positive and critical, and discusses their approach, concepts and methods. In conclusion, it makes a critical assessment of the prospects, and outlines the concept of constitutional order with the purpose of articulating critical reflection on law and the techniques of government today.

KeYwords: constitutional history; law and policy; Constitution; constitutionalism.

\section{RÉSUMÉ}

L'essai traite de la récente production bibliographique européenne sur l'histoire constitutionnelle. En partant de l'exploitation des différents sens de l'expression, il analyse trois points de vue: juridique, positif et critique, et discute leurs approches, csoncepts et méthodes. En conclusion, il fait une évaluation critique des perspectives, et décrit le concept d'ordre constitutionnel pour articuler une réflexion critique sur le droit et les techniques de gouvernement aujourd'hui.

Mots-ClÉs: histoire constitutionnelle; droit et politique; constitution; constitutionnalisme. 


\section{INTRODUÇÃO}

$\mathrm{H}$ istória constitucional designa uma atividade acadêmica que se dedica à história da constituição política dos Estados contemporâneos. Num sentido mais amplo, a expressão se refere a pesquisas em que as manifestações históricas da constituiç̧ão política são tomadas como material ou instrumento de análise. Enfim, num sentido talvez impróprio, o adjetivo "constitucional" pode significar não um objeto de pesquisa, mas uma qualidade ou efeito da temporalidade sobre as formas de vida social, com o que se destaca a sua transitoriedade, os seus processos de produção e reprodução, assim como as modalidades de pensamento sobre elas. Coloca-se o tema dos "efeitos constitutivos da constituição" na história, ou seja, a maneira pela qual ela emergiu em algumas sociedades, os efeitos que produziu e as vias pelas quais ela pode ser superada.

Este ensaio analisa pequena parte da bibliografia europeia recente sobre história constitucional explorando estas três perspectivas: a história que tem por objeto a constituição, a que toma a constituição como suporte para a análise positiva do direito ou da política, e a análise da produção histórica da constituição. Apresenta as suas potencialidades, limites e seu diálogo crítico. Na conclusão, apresenta um balanço das perspectivas e esboça o conceito de ordem constitucional para propor uma abordagem crítica do direito e das técnicas de governo na atualidade que supere o discurso do constitucionalismo.

\section{TEXTO, DOUTRINA, INSTITUIÇÃO}

história constitucional faz parte do ensino universitário em direito, ciência política e
administração pública, tem centros de pesquisa, encontros e seminários temáticos, e tem duas revistas especializadas: História Constitucional, publicada pela Universidade de Oviedo na Espanha, e Giornale de Storia Costituzionale, publicado pelo Laboratorio di Storia Costituzionale Antoine Barnave, da Universidade de Macerata, na Itália, que tem também edição em inglês sob o título Journal of Constitutional History. Tem identidade disciplinar, ou especificidade temática, e propósitos normativos, colocando-se no ponto de encontro entre história do direito, direito constitucional, ciência política e filosofia ou teoria do direito. 
Para essa perspectiva, o seu objeto, a constituição, é delimitado nas relações entre 0 texto normativo, as abstrações conceituais da ciência jurídica e a dimensão formal das instituições políticas. Ela toma como contexto da constituição a dimensão material e concreta das instituições, do processo político e das relações sociais, tratadas por outras disciplinas. Seus materiais de pesquisa são obras de filosofia e publicística, livros de doutrina jurídica, leis, projetos, documentos parlamentares, além de narrativas históricas e memórias. Seu interesse é, sobretudo, pela história nacional, mas desde o pós-Segunda Guerra ela trabalha a história europeia, de modo a fazer confluir as tradições nacionais para a construção da Europa como ideal normativo. Elabora conceitos, instituições e doutrinas comuns da tradição jurídica europeia para informar a preparação de textos legislativos, ilustrar decisões de juízes e administradores, alimentar a reflexão jurídico-doutrinária sobre a constituição e criticar os materiais produzidos do ponto de vista da ciência e a tradição jurídica. ${ }^{1}$

Reflexões acadêmicas sobre a história constitucional são apresentadas nas coletâneas organizadas por Joaquín Varela Suanzes-Carpegna (2015a) e Herrera e Pillouer (2012), em duas edições do Giornale di Storia Costituzionale (n. 19 (1), 2010 e n³0 (2), 2015) e na revista História Constitucional. Nelas se veem as diferenças de ênfase na análise dos elementos texto, doutrina e instituição, assim como as relações entre eles.

Em seu número inicial, o Giornale... afirmou que a história constitucional deve analisar fenômeno constitucional em sua complexidade, como conexão de partes singulares e autônomas, que caracteriza a polifonia do conjunto. 0 seu modelo de história é programaticamente voltado para as fronteiras, pensado e praticado sem ter em conta as tradicionais separações disciplinares. A história constitucional é, então, terreno privilegiado de encontros e conexões de perspectivas distintas (Lacchè, 2002; Lacchè, Martucci e Scuccimarra, 2010). Mais recentemente, foi usada a metáfora do território aberto e do viajante, proposta por Maurizio Fioravanti (2010, 2015), e o último número da revista tem como tema o "polimorfismo constitucional: paradigmas históricos e formatos constitucionais" para evidenciar as relações diversas entre tradição e mudança que se estabelecem em diversas áreas culturais (Lacche, 2015).

Joaquín V. Suanzes-Carpegna (2015b), diretor da revista História Constitucional, privilegia as relações entre os aspectos institucional e doutrinário. A história constitucional é uma disciplina especializada, que se ocupa da gênese e desenvolvimento da constituição do Estado liberal e liberal-democrático. Seu objeto é um conceito substantivo e axiológico de constituição, entendido como fenômeno histórico destinado a limitar o Estado em prol das liberdades individuais. 0 período tratado pela disciplina se inicia com o nascimento desta concepção na Inglaterra do século XVII (Suanzes-Carpegna, 2015b: 13). 
A história constitucional trabalha um direito não vigente, e o que a interessa é a sua gênese e desenvolvimento, e não o resultado a que chegou, que é o objeto do direito constitucional. Seus instrumentos analíticos de pesquisa são os conceitos metaconstitucionais elaborados pela teoria jurídica da constituição. Mas ela também analisa as relações da constituição com o seu contexto político, social e intelectual, para conhecer as lutas em que se deu a produção de conceitos e normas (Suanzes-Carpegna, 2015b: 17-8). Analisa as conexões da constituição com doutrinas e conceitos anteriores e coetâneos, tanto nacionais como estrangeiros e, ainda, o seu impacto normativo, institucional e intelectual. Enfim, a pesquisa é orientada por preocupações com o presente e, por isso, o historiador deve evitar tanto o interesse exclusivo pelo passado sem conexão com o presente quanto a projeção das preocupações e conceitos do presente sobre o passado (Suanzes-Carpegna, 2015b: 29).

Michel Stolleis, antigo diretor do Instituto Max Planck para a História jurídica europeia, em Frankfurt, destaca o papel da ciência do direito para a formação do direito europeu. Seu modelo é o das histórias do direito privado elaboradas na Alemanha após a Segunda Guerra, que estiveram na base da criação daquele instituto. Orientadas pelo propósito de colaborar para a criação do direito europeu, elas procuraram recuperar e reforçar a consciência do ius commune. Inspiradas em Weber, consideram que o direito europeu moderno resulta da racionalização do pensamento jurídico medieval, em que foi central o papel da ciência jurídica na formalização e abstração dos conceitos. Esse processo levou à codificação e à noção do Estado como comunidade de direito com poderes limitados (Stolleis, 2015: 11-17). A tradição do direito culto oferece, então, os moldes para a elaboração dos instrumentos legais e da cultura jurídica para a união da Europa.

Enquanto disciplina, a história do direito é conformada pelo modelo científico do seu tempo. A teoria da ciência elabora os metaconceitos e permite o consenso sobre o que é importante saber, o que é importante ser pesquisado e em qual estrutura ela deve ser preservada para a próxima geração. A ciência do direito fixa teorias e conceitos para a compreensão da legislação e estabelece as bases da compreensão da sua própria dinâmica temporal, ou a história do direito. Esta tem como objeto as ciências do direito do passado e suas relações com outras manifestações do direito (Stolleis, 2010: 45-6). A história constitucional se faz a partir do momento em que a ideia de Constituição (entendida em sentido amplo como decisão básica sobre a comunidade política, dotada de forma jurídica em um ou vários documentos fundamentais) elaborada pela ciência jurídica foi identificada como um fenômeno histórico e passou a fazer parte do processo histórico, isto é, na revolução inglesa (Stolleis, 2009: 481-3).

As ideias constitucionais só emergiram na Europa, e em nenhuma outra parte, porque decorrem do seu enraizamento em tradições jurídicas do continente (Stolleis, 2010). 
As sociedades europeias atuais se concebem como juridicamente constituídas, e o poder deve se legitimar tanto democrática como juridicamente. A fórmula "Europa como comunidade de direito" tem, então, sentido descritivo, por indicar o cerne da construção europeia, e normativo, por vincular o direito atual à sua tradição e destino enquanto comunidade política organizada pelo direito (Stolleis, 2009: 475-6).

Apresentam-se nas próximas seções as críticas a essa perspectiva.

\section{REgRA, INTERESSE, JOGO}

E ssa perspectiva adota uma epistemologia positivista e formula conceitos de caráter operatório, e não histórico, para a análise da constituição. As teorias apresentadas a seguir pensam a constituição como a regra do jogo político para atores racionais, e se distinguem na medida em que seu foco são as normas jurídicas ou os comportamentos individuais.

Indagado por Suansez-Carpegna se a história constitucional teria papel normativo para a construção das instituições europeias, Michel Troper responde que, neste caso, ela seria "uma ideologia mais do que uma empresa científica", pois seria uma empresa de ciência positiva que se limita à descrição, evita juízos de valor e o sincretismo metodológico (Troper, 2015: 52). Ele dá pouca importância à institucionalização acadêmica da história constitucional como disciplina autônoma, discorda que o seu objeto se defina por uma noção axiológica de constituição, como limitação jurídica do poder, e relativiza a importância de critérios factuais para delimitar seu escopo temporal e espacial (Troper, 2015: 53).

Troper considera que a autonomia de uma disciplina se dá pelos seus objetivos, objeto e método, e não por tratar de determinado fenômeno natural ou valor (Troper, 2012: 79). A história constitucional ocupa-se de normas que não são para nós um dever ser porque não estão mais em vigor. Elas são fatos que ocorreram em um determinado momento histórico, cuja forma é a de enunciados normativos. Enquanto tais, elas pertencem a um sistema dotado de autonomia e com relações internas, no qual adquirem significação. Essas relações devem ser explicadas nelas próprias (como dever ser) e não por remissão a outra ordem (ser). Assim, a história constitucional se distingue do direito constitucional atual, que se ocupa da descrição e análise interna das normas jurídicas vigentes, e da história total, ${ }^{2}$ que visa explicar os fatos que deram origem às normas, mas que só as conhece externamente. A contribuição específica da história constitucional para o conhecimento histórico é a análise interna dos sistemas jurídico-constitucionais do passado, o que não é proporcionado pelo direito constitucional, nem pela história total (Troper, 2015: 49; 2012: 76; 2010: 44). 
A realidade que a história constitucional descreve é um modo de argumentação que produz efeitos sociais e políticos. Mas, como os elementos das constituições mudam com 0 tempo e são determinados pelo sistema a que pertencem, ela deve se valer de metaconceitos elaborados pela ciência do direito. Esses conceitos são descritivos, de caráter geral, válidos para qualquer sistema jurídico, e visam explicar as normas, os enunciados de caráter prescritivo que formam o direito. Sua relevância não depende do momento em que foram criados, mas do seu valor operatório para a pesquisa (Troper, 2015: 46; 2012).

A história constitucional pode estabelecer explicações causais, dado que as normas jurídicas são regras para o jogo de atores racionais. Elas impõem as alternativas válidas de ação para que os atores escolham aquela que lhes permite melhor alcançar as suas preferências. Na medida em que impõem constrangimentos aos atores, elas são uma das causas da ação racional em certa situação, ao mesmo tempo em que, complementarmente, as ações traduzem e refazem constantemente as regras do jogo e os seus princípios (Troper, 2015: 47; 2010: 41). A análise enfoca a lógica dos atores ao criar ou modificar as normas jurídicas, a estrutura dos constrangimentos jurídicos que determinaram o seu comportamento e os argumentos que eles utilizaram para fundamentar as suas ações. Ela se interessa em saber o que fizeram os homens do passado e por que o fizeram ao criar uma norma ou aplicá-la de determinada maneira (Troper, 2010: 38).

As constituições escritas a partir do final do século XVIII são as apropriadas para a história constitucional, na medida em que a feitura de uma constituição escrita resulta não só do equilíbrio das forças políticas, mas também dos constrangimentos impostos pelo sistema normativo, que reflete os modos de argumentação dos juristas do seu tempo. Esta história é a da evolução constitucional, compreendida à luz da técnica constitucional, feita pelos juristas-historiadores, que têm os instrumentos para tanto (Troper, 2010: 36).

Então, para Troper, a história constitucional é uma história do direito constitucional, que descreve as normas jurídicas do ponto de vista das relações internas do sistema jurídico ao qual elas pertenciam. Ela realiza análises causais sobre os constrangimentos postos pelas normas para atores racionais e como eles as transformaram por meio de suas ações, resultando em certo padrão de evolução constitucional. Ela pode ser realizada em qualquer país que tenha constituição escrita ou, pelo menos, a noção de hierarquia de normas. Enquanto ciência positiva, ela não tem propósitos normativos, e, portanto, a constituição europeia é um tema como qualquer outro.

A partir dos anos 2000, trabalha-se em ciência política o tema da constitutional choice, ou seja, da formação e manutenção das constituições como resultado de escolhas de atores racionais. 0 objetivo é explicar como e por que atores racionais decidem vincular a si 
mesmos e aos outros a um conjunto de regras obrigatórias, e que têm o efeito de limitar 0 âmbito das suas escolhas e das ações válidas para alcançá-las. E também explicar por que os atores escolhem um determinado desenho institucional e mantêm sua aquiescência às regras mesmo que elas contrariem os seus interesses imediatos.

A coletânea Social and Political Foundations of Constitutions organizada por Denis Galligan \& Mila Versteeg (2013a) resultou de seminários promovidos pela Foundation for Law Justice and Society e o Centre for Socio-Legal Studies na Universidade de Oxford entre 2009 e 2012. A proposta era abordar as constituições como fenômenos políticos e sociais, como parte da "fábrica das nações", o que significa explicá-las do ponto de vista dos indivíduos e em função do contexto social (Galligan \& Versteeg, 2013b: 4).

Os organizadores definem a constituição como um conjunto de regras que criam, empoderam e limitam as instituições governamentais. Ela estabelece um sistema de governo, define os poderes e funções de suas instituições, determina limites substantivos na sua operação e regula as relações entre as instituições e o povo. Mas ela apresenta duas faces: uma é independente e autônoma e tende a se confundir com as normas de um documento escrito, mas que compreende também ideias, convenções e práticas, enquanto a outra é interdependente e entremeada com o contexto social e político. A interação entre esses dois aspectos é a chave para compreender as constituições como instituições sociais. A argumentação e o uso da constituição envolvem processos sociais complexos que inevitavelmente se projetam sobre o contexto social e político mais amplo, levantando questões sobre relações entre 0 contexto e o texto escrito. Assim, as constituições são mais do que documentos escritos e são também instituições sociais que interagem com a sociedade de maneiras complexas (Galligan \& Versteeg, 2013b: 7-8).

A coletânea compreende análises teóricas e estudos de caso sobre as constituições de diversos países no século XX, escolhidos a partir de variáveis para abranger diferentes condições de experiência constitucional.

As análises teóricas discutem a formação, estabilidade e funções da constituição do ponto de vista da racionalidade dos atores. Aqui se dão debates entre os que destacam a função de coordenação das normas, segundo a qual o interesse dos atores pelo bem público proporcionado pelas regras prepondera sobre seus interesses particulares, e os que destacam os efeitos distributivos das normas, enfocando conflitos sobre seu desenho em momentos de mudança constitucional.

Hardin (2013) propõe uma teoria segundo a qual a coordenação funciona como um mecanismo de mercado, no qual indivíduos racionais visam assegurar seus próprios interesses, obtendo vantagens e salvaguardas mútuas. A coordenação é alcançada por uma dupla 
convenção: aquela pela qual o governo deriva seu poder de dominar de uma forma específica e aquela pela qual a população aquiesce a essa dominação. Se a aquiescência for estável por um tempo, ela mantém os incentivos e expectativas com as quais se autoproduz e a ordem adquire segurança e estabilidade. A coordenação é um estado de fato que produz endogenamente regras auto-executáveis às quais os indivíduos aquiescem e, pois, não resulta de um acordo originário e não depende de forma escrita (Hardin, 2013: 69-70). Ela aumenta os custos para fazer as coisas de outro modo, e é provável que suas convenções sejam mantidas, mesmo que contrariem os interesses do povo ou de um grupo particular (Hardin, 2013: 59). Isso implica que há um viés na feitura e manutenção de constituições, pois os povos tendem a manter os arranjos existentes mesmo quando têm oportunidades de modificá-los.

Ginsburg (2013) destaca os efeitos distributivos das normas e formula uma teoria contratual para explicar a elaboração e o conteúdo da constituição. Ele não defende uma teoria normativa do contrato social, nem o pensa como hipotético, mas usa a analogia contratual para explicar situações reais como barganhas em que as partes trocam promessas mútuas, avaliam alternativas e dividem os ganhos. Cláusulas como as da corte constitucional têm conteúdo contratual claro, pois funcionam como termo de segurança, ao criar um fórum alternativo para reconsiderar decisões futuras contrárias à parte que se encontre fora do poder. Ela tende a ser defendida pelos perdedores prospectivos no processo político futuro e a ser adotada quando há uma situação de incerteza política. ${ }^{3}$

Hirschl (2013) propõe uma explicação semelhante a partir de uma abordagem estratégico-realista das constituições, segundo a qual o comportamento estratégico de políticos, elites e cortes é chave para explicar a variação do escopo, natureza e timing das reformas constitucionais (Hirschl, 2013:157-8). As instituições jurídicas produzem efeitos distributivos diferenciais e privilegiam alguns grupos, interesses e preferências políticas em prejuízo de outros. 0 desenho constitucional resulta não apenas de fatores do lado da demanda, como a busca de eficiência do sistema ou de pressões populares pelo reconhecimento de direitos, mas também daqueles do lado da oferta, ou seja, a constelação de poder, assim como os interesses e incentivos dos tomadores de decisão, nas condições políticas que conduziram à mudança constitucional (Hirschl, 2013: 163-5). Os políticos engajados na constitucionalização fazem uma espécie de política de segurança num ambiente político inseguro. A constitucionalização das regras é ideal para entrincheirar interesses e posições de poder, dada a sua duração e dificuldade de reforma. Ao mesmo tempo em que limitam a flexibilidade institucional dos políticos, as regras constitucionais e o judicial review não têm instrumentos de poder e coação diretos.

Assim, essa perspectiva neutraliza as questões relativas à posição do pesquisador, que se coloca na instância da ciência cujo interesse exclusivo é o conhecimento positivo. A 
constituição é reduzida à forma de regras de organização e de conduta, e homogeneizada em séries diacrônicas, relacionadas com variáveis e eventos relevantes. Não se tematizam os efeitos de poder do discurso científico e dos saberes jurídicos, não se discutem as distintas modalidades normativas das constituições, nem suas relações variáveis com outras normatividades sociais, nem tampouco as distintas maneiras pelas quais os agentes se relacionam com elas.

\section{Normatividades, uSOS POlíticos, Hegemonia}

$\mathrm{E}$ sta seção apresenta algumas críticas à história constitucional sob as perspectivas normativa e positiva. Os autores propõem redefinir seu objeto em termos de cultura ou normatividades sociais, encaram as normas como contingentes em função dos seus usos pelos agentes e destacam seu papel na produção da hegemonia política.

Thomas Duve, atual diretor do Instituto Max Planck, tem criticado a tradição da história do direito europeu da qual Stolleis é o expoente em língua alemã. A coletânea Entanglements In Legal History: Conceptual Approaches traz papers apresentados na conferência de mesmo nome realizada no Max Planck Institute for European Legal History, em Frankfurt/Main, em agosto de 2012, cujo objetivo foi estimular pesquisadores a introduzir perspectivas globais na pesquisa sobre a história do direito (Duve, 2014a). Seus argumentos e propostas têm escopo mais amplo do que a história constitucional, mas são inteiramente válidos para este tema.

Duve (2014a) critica a narrativa de uma tradição do ius commune europeu, pois ela adotou o conceito de direito de Savigny concentrado no direito culto e secular, deixando de lado suas interações com outras práticas normativas. Ressalta a continuidade do direito, silenciando sobre os conflitos sociais e políticos nas sociedades europeias, e insiste na singularidade europeia, omitindo suas relações complexas e historicamente cambiantes com outras regiões do mundo.

Duve defende que o pesquisador deve se emancipar das suas próprias tradições eurocêntricas, inclusive as analíticas, tornar-se consciente da sua posicionalidade epistêmica e procurar superá-la por um movimento dialético entre as imagens de si mesmo e dos outros (Duve, 2014a: 7). 0 pesquisador deve conhecer os legados negros da Europa, reconhecer que ela não seria o que é sem o seu passado colonial, e que o seu papel central no mundo é inseparável dos mecanismos de dominação de que se valeu, estabelecidos inclusive pelo direito. A história do direito teria um posicionamento reflexivo, especialização em áreas e abertura intelectual para perspectivas globais. Mas deve manter clara estrutura disciplinar, para evitar a perda de qualidade, embora dialogue e se baseie em estudos de outras disciplinas ou áreas (Duve, 2014c: 56-7). 
Duve propõe uma história do direito europeu em perspectiva transnacional. Ela é europeia em virtude do seu ponto de partida, e se dedica à Europa como uma região global, um importante espaço jurídico que abre as fronteiras e tem relações complexas com outras regiões. Ela se orienta para espaços transnacionais, o que não implica escrever uma história mundial do direito, mas sim delimitar espaços jurídicos flexíveis e mesmo fluídos. Isso significa visar uma história jurídica capaz de estabelecer novas perspectivas, pela abertura a diferentes conceitos analíticos e a fusão destes com sua própria tradição, traçando enredamentos pelo mundo, ou desenhando estruturas compartidas que podem iluminar evoluções históricas paralelas (Duve, 2014b: 4-6; 2014c: 32).

Os conceitos para realizar esse programa são: o de espaços legais dimensionados de forma flexível, conectados e sobrepostos; o de direito como multinormatividade, para compreender formas de normatividade não estruturadas pela ideia de direito; o de tradução cultural, que pensa as trocas culturais do ponto de vista das práticas sociais, do conhecimento e das suas condições concretas; e o de conflito, enfim, que privilegia práticas locais, o conhecimento de senso comum e a diversidade das formas de resolução de conflitos (Duve, 2014c: 58-60).

A coletânea Constitutionalism, Legitimacy, and Power - Nineteenth Century Experiences, dirigida por Kelly Grotke e Markus Prutsch (2014a), resulta de um projeto de pesquisa sobre vocabulários e práticas constitucionais na Europa do século XIX realizado na Universidade de Helsinki entre 2010 e 2011, sob a coordenação de Bo Strath e Martti Koskenniemi. Eles pretenderam obter distanciamento crítico em relação ao discurso dominante atual e liberar a imaginação política para formular alternativas políticas. Mas, ao invés de ampliar o campo de pesquisa a outros domínios, como a cultura, e a espaços transnacionais, investiram na pesquisa da constituição em processo. Estudaram a história política e social em torno das constituições, para reconhecer os determinantes políticos, sociais e culturais de cada projeto político constitucional e alcançar uma compreensão mais nuançada do tempo e espaço constitucionais (Grotke e Prutsch, 2014b: 8-9).

Seu interesse pelo século XIX deve-se ao fato de que naquele período os ideais revolucionários foram integrados à estrutura dos Estados, tornando-se práticas rotinizadas e justificações de suas instituições. A forma constitucional tornou-se recurso privilegiado para forjar o consenso social sobre valores individuais e coletivos, proteções e obrigações dentro de jurisdições delimitadas. Ela funcionava - e continua a funcionar - como uma promessa formalizada, legal, de reconhecimento e integração da multiplicidade de sujeitos na unidade política. A constituição foi instrumento antirrevolucionário, ao colocar o ideal como uma virtualidade postergada do atual e não mais como a sua negação. A linguagem da constituição pretendeu reconciliá-los, indicando um status quo negociado e voltado para um futuro 
idealizado, o que the permitiu conviver com realidades que persistentemente o contrariavam. A mesma combinação e contrariedade entre projeção normativa e práticas atuais de violação está presente em outros pares contrapostos do constitucionalismo, tais como o universalismo e o particularismo, o cosmopolitismo e o nacionalismo, a igualdade legal e a desigualdade social, o liberalismo econômico e o imperialismo (Grotke e Prutsch, 2014b: 13)

Os autores associam a história dos conceitos com dinâmicas institucionais e práticas sociais para mostrar o sentido político dos conflitos a respeito do significado da constituição. Partiram do pensamento jurídico crítico segundo o qual a indeterminação dos conceitos políticos contrasta com a determinação do mundo, porque, se os conceitos são abertos, o mundo não o é. Os conceitos são plataformas com as quais os atores políticos podem promover seus projetos ou contestar os projetos de outros. Mas, como os usos têm distintas consequências distributivas, eles indagaram quem ganha e quem perde com eles. Desse modo, puderam verificar as maneiras como os conceitos operam como legitimadores e também como críticos do mundo, e como os conflitos no mundo puderam ser articulados em termos de entendimentos hegemônicos e contra-hegemônicos de conceitos singulares (Koskenniemi, 2014: vi-viii).

Eles exploraram o vocabulário constitucional num campo formado por dois eixos - por um lado, aquele em que a constituição é associada a progresso, direitos individuais, estabilidade e "excepcionalismo" europeu, e por outro, aquele no qual ela é artifício antirrevolucionário, justificação de desigualdades sociais, promoção do nacionalismo e instrumento do imperialismo. Eles testaram a adequação das afirmações opostas e de suas relações nos casos que estudaram, e suas conclusões são variadas, situando-se no campo formado pelas afirmaçõ̃es opostas. Os estudos de caso apresentam uma narrativa do passado da Europa que não situa a constituição em um ou outro dos lados opostos (Grotke e Prutsch, 2014b: 3-5).

Em suma, essa perspectiva substitui as teorias jurídicas na análise da constituição, utilizando teorias críticas formuladas pelos estudos sócio-jurídicos, os estudos culturais e a história conectada ou global. Os conceitos, normas e sistemas jurídicos são analisados do ponto de vista dos seus usos políticos ou da sua inscrição nas normatividades sociais. 0 objeto convencionalmente conhecido como "direito" é deslocado do centro da cena e pensado como inserido nas condições materiais e simbólicas de sua produção. A tradição jurídica não é valorada positivamente, mas posta em questão em virtude de seu papel na reprodução da dominação. A singularidade do direito europeu é relativizada em função das condições de sua emergência, e sua difusão é redefinida como circulação, comunicação e diálogo com as normatividades de outros espaços culturais. 


\section{Conclusão}

E ste ensaio discutiu três perspectivas de história constitucional que mostram a diversidade e a relevância das pesquisas histórica, política e jurídica sobre o tema. A primeira pensa a constituição na conjunção do texto, das doutrinas e das instituições políticas. A constituição está inserida no processo histórico, e o pesquisador a compreende em suas relações com o contexto social e político. A constituição ter-se-ia realizado nas democracias sociais da atualidade em um processo no qual o historiador do direito e constitucional teria parte ativa. A segunda adota uma epistemologia positivista e procura neutralizar a posição do analista em face da historicidade da constituição assim como as ambivalências desta. A constituição é a regra do jogo político para atores racionais, seu objeto são as normas jurídicas ou o comportamento dos atores. Ela é construída de forma homogênea por meio de séries diacrônicas e relacionada com variáveis ou eventos relevantes. A terceira critica as manifestações históricas da constituição, apontando sua relatividade e seus efeitos de poder. Explora alternativas teóricas para propor problemas e conceitos que apontem suas relações com as normatividades sociais, os usos políticos dos discursos, seu papel na construção da hegemonia.

Para além da afirmação de princípio do pluralismo teórico-metodológico, em que se reconhece e se aceita a irredutibilidade de perspectivas de análise distintas, deve-se levar a sério as críticas, mas também as possíveis respostas dos historiadores juristas. Pode-se imaginar que, em face das críticas, eles reafirmariam a relevância do direito culto europeu para a racionalização do direito escrito e a conformação das instituições e práticas das democracias constitucionais em todo o mundo. A teoria dos constrangimentos jurídicos confirmaria os efeitos produzidos pelo sistema jurídico para as alternativas dos atores. Argumentaria que a ampliação do objeto para o campo das normatividades culturais leva a perder de vista a especificidade do direito constitucional e a reduzir a capacidade de compreensão histórica das constituições contemporâneas. Por sua vez, a afirmação de que o significado dos conceitos jurídicos depende do seu uso e da vontade política e estratégica de utilizá-los enfoca apenas a arbitrariedade do discurso, mas não seu caráter instituído e objetivo, ou não disponível, para os atos individuais dos sujeitos. O sistema jurídico se dissolveria nos seus usos singulares, e corre-se o risco de perder de vista seus efeitos globais de poder.

A pesquisa e reflexão política enfrentam o desafio de ultrapassar o discurso jurídico sobre o direito e a democracia constitucional na atualidade. Então, coloca-se a questão de uma abordagem histórica com enfoque crítico e socialmente enraizado que leve em conta os efeitos gerais de poder do direito e o papel central do saber jurídico nas estratégias de governo das sociedades contemporâneas. Uma possibilidade é partir dos trabalhos de Foucault sobre a 
governamentalidade (2004) para pensar a constituição como um aspecto das tecnologias de poder. Pode-se relacionar as mudanças do direito a partir do século XVIII com as transformações nas técnicas de governo da população, os saberes do modelo da economia política e as instituições da democracia representativa. 0 conceito de ordem constitucional designaria essa ordem de discurso que assume o vocabulário do direito para organizar as relações políticas e sociais, institui a instância judicial como teatro da verdade de toda a sociedade e combina técnicas de soberania, disciplina e governamentalidade para a gestão dos conflitos e desequilíbrios sociais.

\section{Notas}

1 Uma das implicações concretas deste trabalho é o projeto sobre os standards da herança constitucional europeia, patrocinado pela Comissão Europeia da Democracia pelo Direito, ou Comissão de Veneza, o comitê consultivo do Conselho da Europa sobre matérias constitucionais. Ver http://www.venice.coe.int/WebForms/ pages/?p=01_Presentation\&lang=EN. Acesso em 22 de abril de 2016.

2 Este termo tem sentido genérico, pois o autor utiliza várias expressões para designar as disciplinas voltadas para a análise de relações fáticas: história política ou social, história global, ciência política, sociologia etc.

3 Gabriel Negretto (2013) combina os dois enfoques para explicar a mudança constitucional na América Latina. Ver também Gargarella (2012).

\section{REFERÊNCIAS BIBLIOGRÁFICAS}

DUVE, Thomas (org.). Entanglements in legal history: conceptual approaches. Frankfurt: Max Planck Institute For European Legal History, 2014a.

Entanglements in legal history. Introductory remarks. In: Entanglements..., cit., 2014b, p. 3-28. p. 29-66.

European legal history - Concepts, methods, challenges. In: . Entanglements..., cit., 2014c,

FIORAVANTI, Maurizio. Constitucionalismo e história do pensamento jurídico. In: SUANZES-CARPEGNA, Joaquín V. (org.). Historia e historiografía constitucionales - Entrevistas con Ernst-Wolfgang Böckenforde, Michel Troper, Maurice J. C. Vile, Maurizio Fioravanti. Madrid: Ed. Trotta, 2015ª p. 83-108.

. Sulla storia costituzionale. Giornale di Storia Costituzionale, Macerata, vol. 19, n. 1, p. 29-32, 2010.

FOUCAULT. Sécurité, territoire, population. Cours au Collège de France, 1977-8. Paris: Gallimard, 2004.

GALLIGAN, Denis J.; VERSTEEG, Mila (orgs.). Social and political foundations of Constitutions. Cambridge: Cambridge UP, 2013a.

. Theoretical perspectives on the social and political foundations of constitutions. In: Social and political foundations..., cit., 2013b, p. 3-48. 
GARGARELLA, Roberto. Latin American constitutionalism, 1810-2010. Oxford: Oxford U. P., 2013.

GINSBURG, Tom. Constitutions as contract, constitutions as charters. In: GALLIGAN, Denis J.; VERSTEEG, Mila (orgs.). Social and political foundations..., cit., 2013, p. 182-204.

Giornale di Storia Costituzionale. Macerata: Laboratorio di Storia Costituzionale "Antoine Barnave" dell'Università di Macerata (Italia), 1992-. Semestral. Disponível em: http://www.storiacostituzionale.it/.

GROTKE, Kelly; PRUTSCH, Markus (orgs.). Constitutionalism, legitimacy, and power - Nineteenth-century experiences. Oxford: Oxford UP, $2014 a$.

\&__. Introduction. In:___ \&_. Constitutionalism..., cit., 2014b, p. 3-22.

HARDIN, Russel. Why a Constitution? In: GALLIGAN, Denis J.; VERSTEEG, Mila (orgs.). Social and political..., cit., 2013, p. 51-72.

HERRERA, Carlos Miguel; LE PILLOUER, Arnaud. Comment écrit-on I'histoire constitutionnelle? Paris: Kimé, 2012.

HIRSCHL, Ran. The strategic foundations of constitutions. In: GALLIGAN, Denis J.; VERSTEEG, Mila (orgs.). Social and political..., cit., 2013, p. 157-181.

História constitucional, Revista on-line, Oviedo: Universidade de Oviedo. Anual. Disponível em: http://www. historiaconstitucional.com.

KOSKENNIEMI, Martti. Preface. In: GROTKE, Kelly; PRUTSCH, Markus (orgs.). Constitutionalism..., cit., 2014, p. v-ix. LACCHE, Luigi. Una nuova rivista italiana ed europea: II "Giornale Di Storia Costituzionale". Historia Constitucional, Oviedo, vol. 3, p. 301-7, 2002.

. Tra tradizioni e cambiamenti, Giornale di Storia Costituzionale, Macerata, vol. 30, n. 2, p. 5-8, 2015.

; MARTUCCI, Roberto; SCUCCIMARRA, Luca. Per la storia costituzionale, dieci anni dopo. Giornale di Storia Costituzionale, Macerata, vol. 19, n. 1, p. 5-14, 2010.

MARTUCCI, Roberto. Laboratorio di Storia Costituzionale "Antoine Barnave" dell'Università di Macerata (Italia), 1992/2001. Historia Constitucional, Oviedo, n. 2, p. 235-47, 2001.

NEGRETTO, Gabriel. Making constitutions. Presidents, parties, and institutional choice in Latin America. Cambridge: Cambridge UP, 2013.

STOLLEIS, Michael. Europa como comunidad de derecho. Historia Constitucional, Oviedo, vol. 10, 2009, p. 475-484.

Concepts, models and traditions of a comparative European constitutional history. Giornale di Storia Costituzionale, Macerata, vol. 19, n. 1, p. 45-57, 2010.

Traditions and changes and the role of legal history. Giornale de Storia Costituzionale, Macerata, vol. $30, n^{\circ} 2$, p. 11-17, 2015.

SUANZES-CARPEGNA, Joaquín V. (org.). Historia e historiografía constitucionales - Entrevistas con Ernst-Wolfgang Böckenforde, Michel Troper, Maurice J. C. Vile, Maurizio Fioravanti. Madrid: Ed. Trotta, 2015a.

. La historia constitucional: algunas reflexiones metodológicas. In: . Historia e historiografía...,

cit., 2015b, p. 13-29. 
ANDREI KOERNER

TROPER, Michel. L'autonomie de I'histoire constitutionelle. Giornale di Storia Costituzionale, Macerata, v. 19, n. 1, p. 33-44, 2010.

Les concepts de I'histoire constitutionnelle. In: HERRERA, Carlos Miguel; LE PILLOUER, Arnaud (orgs.). Comment écrit-on I'histoire constitutionnelle?, cit., 2012, p. 75-94.

. La dimensión histórica del constitucionalismo. In: SUANZES-CARPEGNA, Joaquín V. (org.). Historia e historiografía constitucionales, cit., 2015, p. 43-57. 